\title{
Pengaruh koreksi bias dan metode ensemble pada data curah hujan dari empat model luaran Regional Climate Model (RCM) CORDEX-SEA di Sumatera
}

\section{Effect of bias correction and ensemble method on rainfall data from four output regional climate model (RCM) CORDEX-SEA over Sumatera}

\author{
Irza Arnita Nur ${ }^{\mathrm{ab}}$, Rahmat Hidayat $^{\mathrm{c}}$, Arnida Lailatul Latifah $^{\mathrm{d}}$, Misnawati $^{\mathrm{e}}$

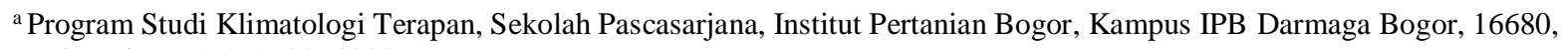 \\ Indonesia [+62 85290864004] \\ ${ }^{\mathrm{b}}$ Pusat Penelitian Lingkungan Hidup, Lembaga Penelitian dan Pengabdian kepada Masyarakat, Institut Pertanian Bogor, Kampus \\ IPB Darmaga Bogor, 16680, Indonesia \\ ${ }^{\mathrm{c}}$ Departemen Geofisika dan Meteorologi, Institut Pertanian Bogor, Kampus IPB Darmaga Bogor, 16680, Indonesia \\ ${ }^{\mathrm{d}}$ Research Center for Informatics, LIPI, Cibinong Bogor, Indonesia \\ ${ }^{\mathrm{e}}$ Balai Penelitian Agroklimat dan Hidrologi Indonesia, Kementerian Pertanian, Bogor, Indonesia
}

\section{Article Info:}

Received: 06 - 01 - 2021

Accepted: 08 - $03-2021$

Keywords:

Bias correction, CHIRPS, CORDEX-SEA, rainfall

Corresponding Author:

Irza Arnita Nur

Program Studi Klimatologi

Terapan, Sekolah Pascasarjana,

Institut Pertanian Bogor;

Tel. +6285290864004

Email:

irzaarnitanur@gmail.com

\begin{abstract}
Drought is a natural disaster that occurs slowly and lasts longer until the wet season occurred. Drought occurs in an expected time so that preparations and preparedness can be made in dealing with drought disasters. Therefore, we need an overview of future drought events (or projections). In this study, Standardized Precipitation Index (SPI) was used as a drought index. The occurrence of drought is closely related to weather factors and occurs repeatedly. Time-series weather data is needed to know the time-series weather conditions. Problems with data that often occur can be overcome by anumerical climate modeling, which is currently widely used. Regional Climate Model (RCM) is a climate model that can be used to build long-term climate data, both time-series and projection data. The results showed RCM model data required bias correction to reduce bias in the CORDEX-SEA RCM model data. RCM rainfall models before correction were still biased. Thus, bias correction is needed to reduce bias in models' data. The results showed ensemble model correction value is the closest to the CHIRPS observation rainfall pattern with $r=0.97$. The average annual rainfall during 2000-2005 showed an ensemble model is the closest to the CHIRPS observation with a range of 2500-3000 mm/year.
\end{abstract}

How to cite (CSE Style $8^{\text {th }}$ Edition):

Nur IA, Hidayat R, Latifah AL, Misnawati. 2021. Perbandingan curah hujan sebelum dan sesudah dikoreksi bias menggunakan empat model luaran reginoal climate model (RCM) CORDEX-SEA di Pulau Sumatera. JPSL 11(1): 49-56. http://dx.doi.org/10.29244/jpsl.11.1.49-56.

\section{PENDAHULUAN}

Perubahan iklim akan mengakibatkan peningkatkan kejadian ekstrem, seperti perubahan intensitas curah hujan. Seperti curah hujan ekstrem, suhu udara ekstrem, intensitas badai dan tornado, serta perubahan percepatan siklus hidrologi di permukaan bumi yang ditandai dengan meningkatnya frekuensi bencana (Handoko, 2020). Salah satu bencana yang sering terjadi di Indonesia adalah terjadinya curah hujan ekstrem yaitu ekstrem basah maupun ekstrem kering. Kejadian curah hujan ekstrem kering atau kekeringan sangat 
berpengaruh dalam berbagai sektor, seperti sektor pertanian, kehutanan, perkebunan, dan lingkungan. Pulau Sumatera merupakan pulau yang sangat merasakan dampak dari kejadian curah hujan ekstrem, karena Pulau Sumatera memiliki semua sektor tersebut.

Peristiwa terjadinya kekeringan merupakan bencana alam yang erat kaitannya dengan faktor cuaca dan terjadi secara berulang. Oleh karena itu, diperlukan data cuaca yang cukup panjang untuk mengetahui history keadaan cuaca sebelumnya. Jenis unsur iklim yang diamati dan periode pengamatan pun masih terbatas. Probelematika kelengkapan data iklim di Indonesia masih sulit untuk diperoleh, baik dari kelengkapan panjang data mapupun dari lokasi yang diinginkan.

Permasalahan mengenai data yang sering terjadi dapat diatasi dengan pemodelan iklim numerik yang saat ini sudah banyak digunakan. Global Climate Model (GCM) adalah model iklim yang dapat digunakan untuk membangun data iklim jangka panjang baik data history maupun proyeksi (Wigena, 2006). Informasi data iklim historis dan proyeksi yang memiliki skala spasial dan temporal tinggi diperlukan dalam kajian iklim pada skala regional yaitu pada cakupan wilayah Pulau Sumatera. Namun GCM memiliki kekurangan yaitu masih berskala global dengan hasil luaran yang juga memiliki resolusi spasial yang kasar (100-250) km skala spasial dan bila digunakan untuk kajian pada skala regional tidak memadai (Salathe Jr., 2003). Sulitnya mendapatkan informasi skala lokal atau regional tersebut sekarang dapat diselesaikan dengan menggunakan model iklim regional (Regional Climate Models/RCM) dengan melakukan pendekatan downscaling statistik maupun dinamik untuk memperoleh informasi iklim dengan resolusi tinggi dan lebih detail.

Output dari simulasi RCM biasanya masih memiliki bias dan dapat memberikan informasi yang berbeda baik secara temporal juga spasial dibandingkan menggunakan data observasi (Christensen et al., 2008; Teutschbein dan Siebert, 2010; Varis et al., 2004). Penelitian ini mengadopsi metode yang digunakan oleh Piani et al. (2010). Secara spesifik, metode Piani et al. (2010) digunakan untuk memperbaiki distribusi data luaran model, sehingga mendekati distribusi data observasi.

Tujuan Penelitian ini dilakukan untuk membandingkan data model luaran RCM CORDEX-SEA sebelum dan sesudah dikoreksi bias dengan data observasi di Pulau Sumatera dengan baseline tahun 2000-2005.

\section{METODE}

\section{Lokasi dan Waktu Penelitian}

Penelitian ini dilakukan dengan menggunakan luaran data model luaran RCM CORDEX-SEA yang diperoleh dari LIPI Cibinong Bogor yang bekerjasama dengan BMKG. Penelitian dilakukan dari bulan September 2019 sampai Agustus 2020. Wilayah kajian penelitian yang dilakukan yaitu Pulau Sumatera dengan tahun SPI historis yaitu dari tahun 2000-2005.

\section{Metode Penelitian}

Data yang digunakan dalam penelitian ini adalah data curah hujan curah hujan harian CHIRPS tahun 2000-2005 yang diunduh dari IRI Data Library dengan alamat website http://iridl.ldeo.columbia.edu/SOURCES/.UCSB/.CHIRPS/ atau data juga dapat di unduh langsung dari website http://chg.geog.ucsb.edu/data/chirps/, data hujan bulanan model RCM. Penelitian ini menggunakan 4 model RCM, yaitu CSIRO-MK3-6-0, GFDL-ESM2M, IPSL-CM5A-LR dan MPI-ESM-MR, dan ensemble model yaitu rata-rata dari keempat model. Data model CORDEX-SEA didapatkan dari LIPI yang berkerjasama dengan BMKG dengan resolusi masing-masing 0.250 x 0.250. Tabel 1 merupakan berbagai jenis data luaran model RCM CORDEX-SEA serta tahun yang digunakan untuk diteliti dalam penelitian. Sedangkan, alat yang digunakan dalam penelitian yaitu meliputi beberapa software seperti Matlab, Bitvise, ArcGIS, dan Ms. Office. 
Tabel 1 Data model luaran RCM CORDEX-SEA dan tahun baseline serta tahun skenario RCP (Perez et al., 2014)

\begin{tabular}{|c|c|c|c|c|}
\hline No & Model & Institusi & $\begin{array}{l}\text { Resolusi Atmosfer (Lat } \\
\text { x lon), Layer }\end{array}$ & Baseline \\
\hline 1. & CSIRO MK3.6 & $\begin{array}{l}\text { CSIRO Atmospheric } \\
\text { Research (Australia) }\end{array}$ & $1.9^{\circ} \times 1.9^{\circ}, \mathrm{L} 18$ & $2000-2005$ \\
\hline 2. & GFDL-ESM2M & $\begin{array}{l}\text { Geophysical Fluid } \\
\text { Dynamics Laboratory } \\
\text { (USA) }\end{array}$ & $\begin{array}{l}2^{\circ} \times 2.5^{\circ} \\
\mathrm{L} 24\end{array}$ & $2000-2005$ \\
\hline 3. & IPSL-CM5A-LR & $\begin{array}{l}\text { Institut Pierre Simon } \\
\text { Laplace (Perancis) }\end{array}$ & $\begin{array}{l}2.5^{\circ} \times 3.75^{\circ} \\
\quad \mathrm{L} 24\end{array}$ & $2000-2005$ \\
\hline 4. & MPI-ESM-LR & $\begin{array}{l}\text { Max Planck Institute for } \\
\text { Meteorology (Jerman) }\end{array}$ & $1.9^{\circ} \times 1.9^{\circ}, \mathrm{L} 31$ & 2000-2005 \\
\hline
\end{tabular}

\section{Metode Analisis Data}

\section{Koreksi Bias Curah Hujan Observasi dan RCM Model}

Koreksi data curah hujan dilakukan dengan metode distribution mapping atau metode piani. Koreksi bias metode distribution mapping merupakan salah satu cara mengoreksi data dengan pendekatan koreksi terhadap distribusi data (Piani et al., 2010). Metode koreksi distribusi yang digunakan dalam penelitian ini adalah metode yang mengidentifikasi jenis distribusi peluang curah hujan observasi dan curah hujan model, curah hujan model dalam penelitian ini adalah curah hujan model luaran CORDEX-SEA. Bentuk distribusi peluang curah hujan pada dasarnya mengikuti distribusi gamma sebagai bentuk distribusi yang cocok untuk kajian klimatologi curah hujan. Oleh karena itu, dalam penelitian ini curah hujan observasi yaitu curah hujan CHIRPS dan curah hujan model luaran RCM CORDEX-SEA diasumsikan mengikuti distribusi gamma, maka langkah pertama koreksi bias metode ini adalah menghitung fungsi kepadatan peluang (Probability Distribution Function (PDF)) curah hujan observasi dan CHIRPS berdasarkan distribusi gamma dengan menggunakan persamaan berikut:

Dimana:

$$
p d f(x)=\frac{e^{\left(-\frac{x}{b}\right)} x^{a-1}}{\Gamma(a) b^{a}}
$$

$\mathrm{x}=$ curah hujan harian rata-rata $(\mathrm{mm})$

$\mathrm{a}=$ parameter bentuk sebaran gamma

$\mathrm{b}=$ parameter skala sebaran gamma

$\Gamma=$ fungsi gamma

PDF curah hujan observasi dan model RCM dihitung per bulan dengan memisahkan dan menyusun kembali curah hujan harian tahun 2000-2005 berdasarkan bulan, sehingga diperoleh series data sebanyak 12 bulan untuk setiap grid curah hujan.

Langkah kedua yaitu membuat hubungan fungsi transfer distribusi kumulatif gamma (Inverse Gamma Cumulative Distribution Functions (CDFs)) masing-masing bulan antara data curah hujan observasi CHIRPS dengan data curah hujan model luaran RCM CORDEX-SEA.

$$
c d f(x)=\int_{0}^{x} \frac{e^{\left(-\frac{x}{b}\right)} x^{\prime(k-1)}}{\Gamma(k) \theta^{k}} d x^{\prime}+c d f(0)
$$


Langkah ketiga adalah menentukan fungi transfer $\mathrm{y}=\mathrm{f}(\mathrm{x})$ yang dapat berupa persamaan regresi linear atau polinomial untuk mengoreksi data curah hujan RCM model luaran CORDEX-SEA. Simulasi yang dilakukan oleh Jadmiko et al., (2017) menunjukkan bahwa persamaan regresi yang menghasilkan curah hujan model terkoreksi paling mendekati curah hujan observasi adalah persamaan regresi polinomial orde 3 dengan nilai intersep pada titik (0.0) dengan bentuk persamaan sebagai berikut:

$$
y=a_{0}+a_{1} x+a_{2} x^{2}+a_{3} x^{3}
$$

Setelah jenis fungsi transfer ditentukan untuk masing-masing bulan (Januari-Desember), maka fungsi transfer tersebut digunakan sebagai faktor koreksi untuk mengoreksi data bulanan model RCM dengan memasukkan data bulanan curah hujan model luaran RCM CORDEX-SEA yang belum terkoreksi (x) ke dalam persamaan fungsi transfer tersebut sesuai dengan bulan masing-masing sehingga diperoleh model luaran RCM CORDEX-SEA terkoreksi (y) bulanan untuk semua grid.

\section{HASIL DAN PEMBAHASAN}

\section{Hasil Koreksi Bias Curah Hujan CHIRPS dengan RCM model CORDEX-SEA}

Metode distribution mapping digunakan karena metode koreksi ini memperbaiki distribusi data yang ada. Koreksi bias dilakukan yakni mengoreksi data model luaran RCM CORDEX-SEA dengan data CHIRPS. Data CHIRPS merupakan data curah hujan harian, bulanan, bahkan tahunan berbasis grid yang menggabungkan data pos hujan dan data satelit. Luaran CHIRPS yang berupa grid menjadikan CHIRPS lebih masuk akal untuk digunakan sebagai input pada analisis yang membutuhkan data curah hujan (Funk et al., 2015; Yanto et al., 2017; Thomson et al., 2017). Dari berbagai hasil penelitian yang menunjukkan kehandalan CHIRPS dalam melengkapi ataupun menggantikan data observasi yang kosong, maka dalam penelitian ini CHIRPS juga digunakan sebagai substitusi data observasi di daerah penelitian.
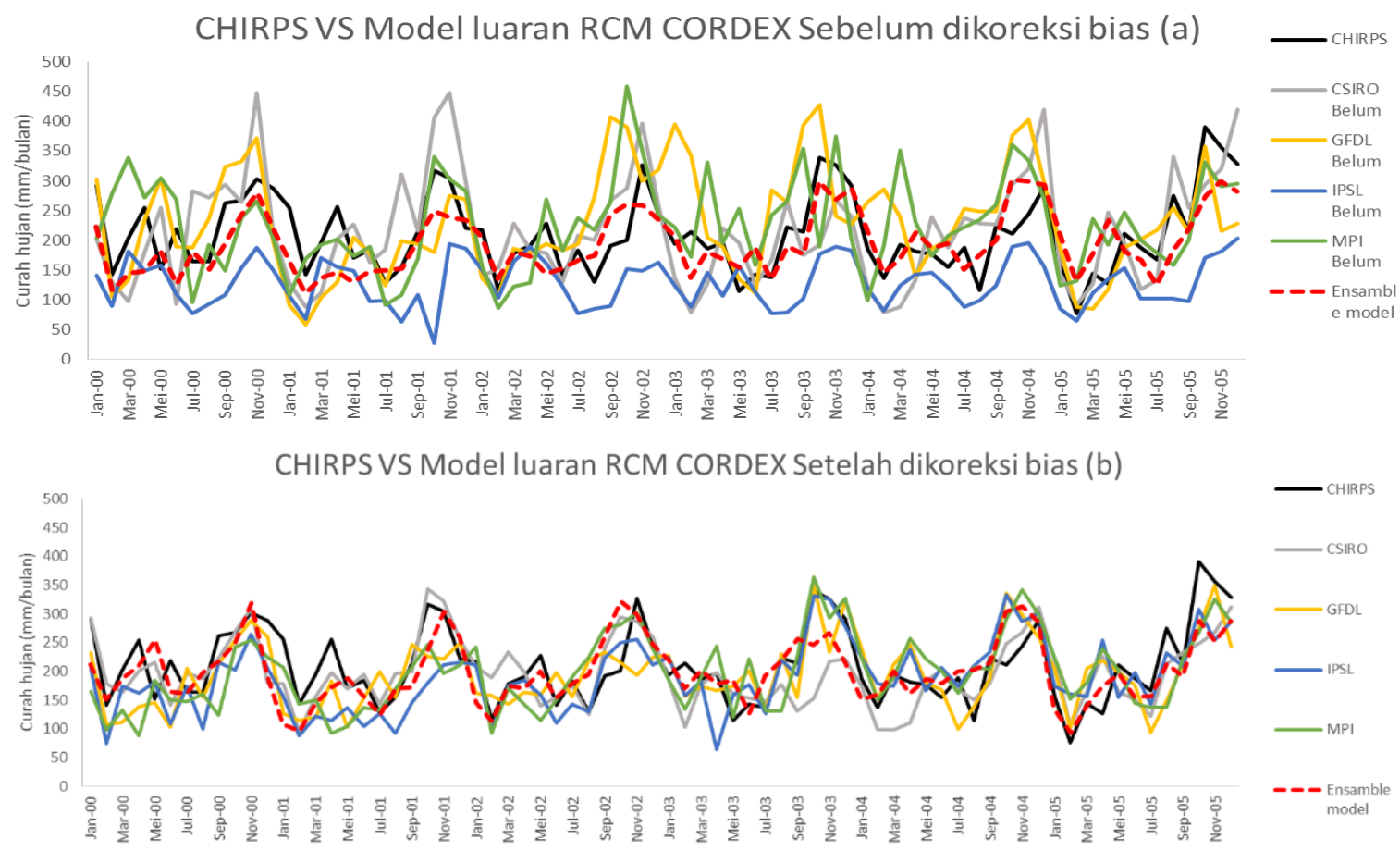

Gambar 1 Perbandingan data historis curah hujan bulanan model luaran RCM CORDEX-SEA dengan data CHIRPS, (a) sebelum di koreksi bias, (b) sesudah dikoreksi bias 
Gambar 1 menunjukkan time series curah hujan bulanan historis dari tahun 2000-2005 di Pulau Sumatera. Gambar 1(a) menunjukkan rentang garis tiap model tidak mengikuti pola dari curah hujan observasi yaitu curah hujan CHIRPS (warna hitam) dan model ensemble (warna merah garis putus-putus). Time series model RCM CORDEX-SEA yang berada di atas garis hitam menunjukkan nilai curah hujan overestimate, sedangkan yang berada di bawah garis hitam berarti underestimate dari nilai curah hujan observasi.

Gambar 1(b) menunjukkan perbedaan yaitu nilai curah hujan model yang telah dilakukan koreksi bias. Rentang nilai antar model tidak terlalu berbeda jauh. Curah hujan RCM model lebih mengikuti time series curah hujan observasi dan time series. Time series nilai ensamble model teroreksi merupakan time series yang paling mengikuti pola curah hujan observasi daripada model RCM lain. Ensemble model menunjukkan performa yang lebih baik dari pada masing-masing model. Nilai ensemble RCM setelah dikoreksi menunjukkan nilai yang lebih sedikit underestimate dan overestimate karena data sudah terkoreksi.

Tabel 2 Perbandingan hasil analisis statistik hubungan antara curah hujan model luaran RCM CORDEX-

SEA dan ensemble model dengan curah hujan observasi (CHIRPS) sebelum dan sesudah terkoreksi di wilayah Pulau Sumatera berdasarkan koefisien korelasi dan pvalue

\begin{tabular}{cccccccc}
\hline \multirow{2}{*}{ Tahun } & \multirow{2}{*}{ Model RCM } & \multicolumn{3}{c}{ Sebelum dikoreksi bias } & \multicolumn{3}{c}{ Setelah dikoreksi bias } \\
& & $\mathrm{R}^{2}$ & $\mathrm{r}$ & pvalue & $\mathrm{R}^{2}$ & $\mathrm{r}$ & pvalue \\
\hline $2000-2005$ & CSIRO & 0.89 & 0.94 & 0.00 & 0.93 & 0.96 & 0.00 \\
$2000-2005$ & GFDL & 0.87 & 0.93 & 0.00 & 0.92 & 0.95 & 0.00 \\
$2000-2005$ & IPSL & 0.91 & 0.95 & 0.00 & 0.92 & 0.95 & 0.00 \\
$2000-2005$ & MPI & 0.88 & 0.93 & 0.00 & 0.91 & 0.95 & 0.00 \\
$2000-2005$ & ensemble & 0.94 & 0.96 & 0.00 & 0.95 & 0.97 & 0.00 \\
\hline
\end{tabular}

Nilai mengenai koefisien korelasi (r) dan pvalue dilihat dari sebelum dikoreksi ditunjukkan oleh Tabel 2. Nilai curah hujan luaran RCM CORDEX-SEA setelah dilakukan koreksi bias mengalami peningkatan nilai r, dari pada sebelum dilakukan koreksi bias. Nilai koefisioen korelasi model CSIRO sebelum koreksi yaitu 0.94 setelah koreksi 0.96, nilai r GFDL sebelum dikoreksi yaitu 0.93 setelah dikoreksi yaitu 0.95, nilai r IPSL sebelum dikoreksi yaitu 0.91 setelah dikoreksi yaitu 0.92 , dan nilai r MPI sebelum dikoreksi yaitu 0.88 setelah dikoreksi yaitu 0.91. Hal ini menunjukkan nilai curah hujan setelah dikoreksi nilai $r$ meningkat dan nilainya diatas 0.9 semua. Nilai ensamble rata-rata dari keempat model tersebut mengalami kenaikan nilai $r$. Nilai $r$ sebelum dikoreksi yaitu 0.94 meningkat menjadi 0.97. Dari keempat model di atas untuk model RCM nilai $r$ yang paling besar antara curah hujan CHIRPS vs curah hujan model, yaitu model RCM CSIRO sebesar 0.96. Sedangkan nilai ensamble menunjukkan nilai r yang paling besar daripada keempat model RCM lainnya yaitu 0.97. Nilai $\mathrm{r}$ yang besarnya mendekati 1 menunjukkan adanya hubungan yang erat antara curah hujan model RCM ataupun ensemble dengan curah hujan CHIRPS, sehingga curah hujan CHIRPS yang paling memiliki hubungan erat dengan ensemble model. Hal ini menunjukkan performa yang memiliki kaitan paling erat dengan data observasi daripada model RCM lainnya. Nilai pvalue yang diperoleh pun semua sama sebelum dan sesudah model dikoreksi, yaitu bernilai 0 . Nilai $\alpha=0.05$ sehingga nilai pvalue $(0.00)<\alpha(0.05)$ hal ini menunjukkan bahwa data model dan observasi CHIRPS memiliki hubungan yang signifikan serta berpengaruh satu dengan yang lainnya.

Pulau Sumatera merupakan wilayah dengan dua tipe curah hujan yaitu tipe curah hujan monsoonal dan curah hujan ekuatorial sesuai penelitian yang dilakukan Aldrian et al. (2003). Pola curah hujan sebelum dan sesudah dikoreksi bias menunjukkan nilai curah hujan model luaran RCM CORDEX-SEA seperti pada Gambar 2. Pola curah hujan setelah dikoreksi terlihat berbeda, dimana pola curah hujan monsoonal (Gambar 2a) bersifat unimodial (satu puncak musim hujan). Bulan Februari, Maret dan April termasuk bulan kering, sedangkan bulan September, Oktober dan November merupakan bulan basah dan enam bulan sisanya merupakan periode peralihan atau pancaroba. Hermawan (2010) menyebutkan bahwa tiga bulan peralihan musim kemarau ke musim hujan dan tiga bulan peralihan musim hujan ke musim kemarau. Pola curah hujan 
ekuatorial terlihat pada Gambar $2 \mathrm{~b}$ yaitu dengan membentuk 2 puncak musim penghujan dalam satu tahun. Tipe curah hujan dengan bentuk bimodial (dua puncak hujan) dimana ada 2 puncak penghujan yang terjadi yaitu bulan April dan Desember. Selain dilihat dari hubungan antara curah hujan model dan observasi, perlu dilihat juga curah hujan dari segi pola spasialnya.

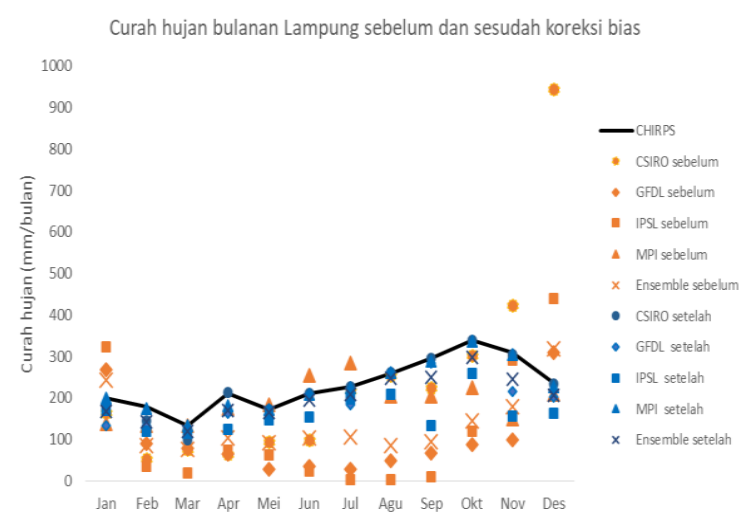

(a)

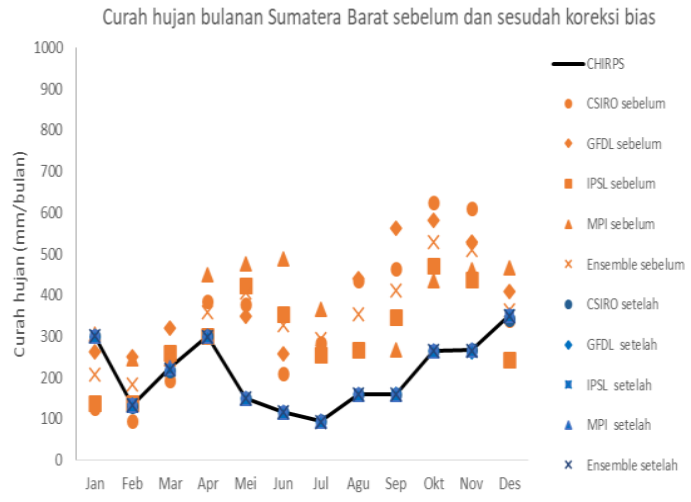

(b)

Gambar 2 Pola curah hujan rata-rata bulanan di Pulau Sumatera, (a) wilayah di Pulau Sumatera dengan pola curah hujan monsoonal (b) wilayah di Pulau Sumatera dengan pola curah hujan ekuatorial

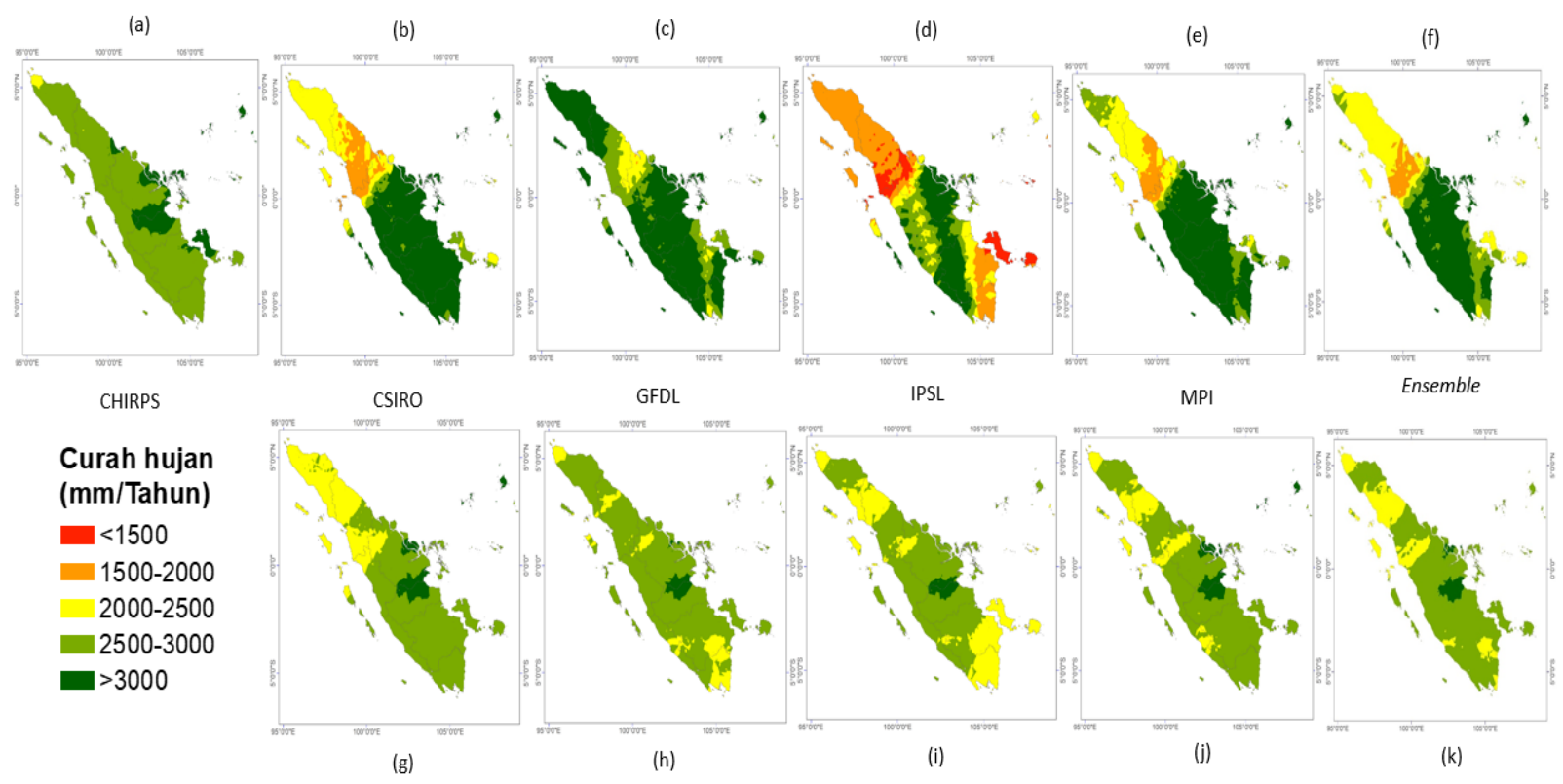

Gambar 3 Perbandingan curah hujan spasial sebelum dan setelah data dikoreksi bias antara data observasi dan model luaran RCM CORDEX-SEA, (a) data observasi yaitu CHIRPS. Data curah hujan yang belum dikoreksi: (b) CSIRO, (c) IPSL, (d) GFDL, (e) MPI, (f) ensemble model. Data curah hujan setelah dikoreksi bias: (f) CSIRO, (g) IPSL, (h) GFDL, (i) MPI, (k) ensemble model

Gambar 3 menunjukkan pola spasial dan besarnya curah hujan tahunan dari CHIRPS sebelum dilakukan koreksi (Gambar 3b-3f) memiliki perbedaan dengan pola spasial dari curah hujan observasi CHIRPS (Gambar 6a). Koreksi bias yang telah dilakukan menghasilkan gambar pola spasial curah hujan rata-rata tahunan (Gambar 3g-3k) menunjukkan besarnya nilai curah hujan antara curah hujan observasi dengan model terdapat kemiripan. Gambar 6b-6e nilai curah hujan model luaran RCM CORDEX-SEA, masih terlihat banyak yang berwarna merah dan oranye hal itu mengindikasikan bahwa pola spasial model sebelum dikoreksi bias masih 
underestimate, hal ini terlihat di wilayah Sumatera Utara, Aceh, sedangkan warna hijau tua yang lebih mendominasi pun dikategorikan overestimate dari nilai observasi yaitu hampir terjadi di seluruh wilayah Sumatera terutama wilayah Lampung, Bengkulu, Sumatera Selatan, Jambi, Riau, dan Sumatera Barat. Gambar 3f yang merupakan nilai ensemble pun masih menunjukkan nilai curah hujan rata-rata tahunan overestimate dan underestimate dari nilai observasi.

Curah hujan spasial rata-rata tahunan yang telah dikoreksi di Pulau Sumatera menunjukkan perbedaan hasil dengan pola spasial rata-rata curah hujan yang belum dikoreksi. Pola spasial model memiliki kemiripan dengan pola spasial curah hujan observasi. Wilayah Lampung, Bengkulu, Sumatera Selatan dan Riau sudah didominasi oleh warna hijau muda seperti pola spasial curah hujan rata-rata observasi. Gambar $3 \mathrm{k}$ menunjukkan ensemble keempat model RCM yang telah dirata-rata menunjukkan hasil kemiripan dengan model MPI. Hasil koreksi bias nilai curah hujan rata-rata di Pulau Sumatera masih terdapat beberapa nilai underestimate yang ditunjukkan oleh warna kuning di beberapa wilayah Lampung, Sumatera Utara dan Aceh. Nilai rata-rata curah hujan yang mendominasi Pulau Sumatera menurut data observasi atau CHIRPS yaitu sekitar 2500 hingga $3000 \mathrm{~mm} /$ tahun.

\section{KESIMPULAN}

Dari penelitian ini, disimpulkan bahwa data curah hujan model RCM sebelum dikoreksi masih memiliki bias, sehingga untuk mengurangi bias pada data diperlukan koreksi bias. CHIRPS digunakan sebagai data observasi, sehingga hasil data curah hujan model RCM setelah terkoreksi mengikuti pola data curah hujan observasi. Ensemble model merupakan model yang paling mendekati nilai observasi dengan nilai korelasi $\mathrm{r}$ yang paling besar yaitu 0.97, sehingga curah hujan observasi paling memiliki hubungan erat dengan ensemble model. Hal ini menunjukkan performa yang memiliki kaitan paling erat dengan data observasi daripada model RCM CORDEX-SEA lainnya. Nilai ensamble curah hujan rata-rata tahunan pun menunjukkan bahwa model ensemble mendekati nilai curah hujan observasi rata-rata tahunan dari tahun 2000-2005 yaitu sebesar 2500 hingga $3000 \mathrm{~mm} /$ tahun.

\section{DAFTAR PUSTAKA}

Aldrian E, Sutanto RD. 2003. Identification of three dominant rainfall regions within Indonesia and their relationship to sea surface temperature. Int Journal of Climatolgy. doi: 10.1002/joc.950.

Christensen JH, Boberg F, Cristensen OB, Lucas-Picher P. 2008. On the need for bias correction of regional climate change projections of temperature and precipitation. Geophys Res Lett. 35(20): 1-6. doi: 10.1029/2008GL035694.

Funk CC, Verdin A, Michaelsen J, Peterson P, Pedreros D, Husak G. 2015. A global satellite-assisted precipitation climatology. Earth Syst Sci Data. 7: 275-287. doi: 10.5194/essdd-8-401-2015.

Handoko U. 2020. Tata ruang tangguh bencana iklim di DAS Batanghari [disertasi]. Bogor (ID): Institut pertanian Bogor.

Hermawan E. 2010. Pengelompokan pola curah hujan yang terjadi di beberapa kawasan Pulau Sumatera berbasis hasil analisis teknik spectral. Jurnal Meteorologi dan Geofisika. 11(2): 75-85.

Jadmiko SD, Murdiyarso D, Faqih A. 2017. Koreksi bias luaran model iklim regional untuk analisis kekeringan. Jurnal Tanah dan Iklim. 41(1): 32-45. doi: 10.4269/ajtmh.16-0696.

Perez J, Melisa M, Fernando JM, Inigo JL. 2014. Evaluating the performance of CMIP3 and CMIP5 global climate models over the north-east Atlantic region. Clim Dyn. doi: 10.1007/s00382-014-2078-8.

Piani C, Haerter JO, Coppola E. 2010. Statistical bias correction for daily precipitation in regional climate models over Europe. Theor Appl Climatol. 99: 187-192.

Salathe Jr EP. 2003. Comparison of various precipitation downscaling method for the simulation of streamflow in a rainshadow river basin. Int J Climatol. 23(8): 887-901. doi: 10.1002/joc.922. 
Teutschbein C, Seibert J. 2010. Regional climate model for hydrological impact studies at the catchment scale: a review of recent modelling stategies. Geogr Compass. 4(7): 834-860. doi: 10.1111/j.17498198.2010.00357.x.

Thomson MC, Ukawuba I, Hershey CL, Bennett A, Ceccato P, Lyon B, Dinku T. 2017. Using rainfall and temperature data in the evaluation of national malaria control programs in Africa. Am J Trop Med Hyg. 97: 32-45.

Varis O, Kajander T, Lemmela R. 2004. Climate and water: from climate models to water resources management and vice versa. Climatic Change. 66(3): 321-344. doi: 10.1023/B:CLIM.0000044622.42657.d4.

Wigena AH. 2006. Statistical Downscaling Luaran GCM. Bogor (ID): Institut Pertanian Bogor.

Yanto, Livneh B, Rajagopalan B. 2017. Data descriptor: Development of a gridded meteorological dataset over Java Island, Indonesia 1985-2014. Scientific Data. doi: 10.1038/Sdata.2017.72. 